This item was submitted to Loughborough's Research Repository by the author.

Items in Figshare are protected by copyright, with all rights reserved, unless otherwise indicated.

\title{
Numerical investigation on fluid flow of gear lubrication
}

PLEASE CITE THE PUBLISHED VERSION

http://dx.doi.org/10.4271/2008-01-1650

PUBLISHER

(C) SAE International

VERSION

AM (Accepted Manuscript)

LICENCE

CC BY-NC-ND 4.0

REPOSITORY RECORD

Li, Li, Hendrik K. Versteeg, Graham K. Hargrave, Theo Potter, and Chris Halse. 2019. "Numerical Investigation on Fluid Flow of Gear Lubrication". figshare. https://hdl.handle.net/2134/13372. 
This item was submitted to Loughborough's Institutional Repository (https://dspace.lboro.ac.uk/) by the author and is made available under the following Creative Commons Licence conditions.

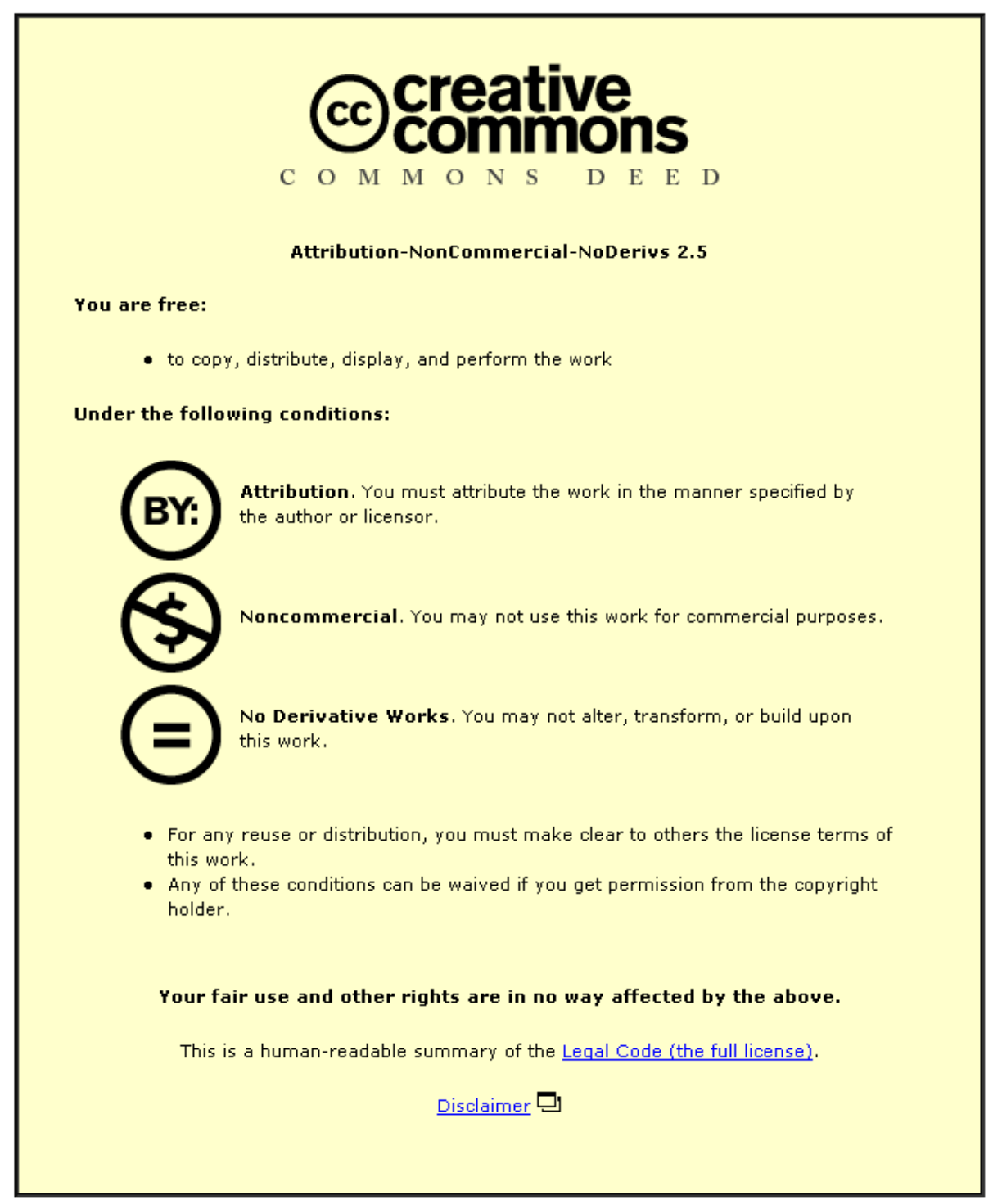

For the full text of this licence, please go to: http://creativecommons.org/licenses/by-nc-nd/2.5/ 


\title{
Numerical Investigation on Fluid Flow of Gear Lubrication
}

\author{
Li Li $^{1,2}$, Henk K Versteeg ${ }^{1}$, Graham K Hargrave ${ }^{1}$, Theo Potter ${ }^{2}$, Chris Halse ${ }^{2}$ \\ ${ }^{1}$ The Wolfson School of Mechanical \& Manufacturing Engineering, Loughborough University, UK \\ ${ }^{2}$ Romax Technology Ltd, UK
}

Copyright $\odot 2008$ SAE International

\begin{abstract}
Several details of the mechanism of gear lubrication are still in doubt in spite of many decades of study of this subject. The focus of our work is the investigation of the mechanism by which oil $^{\dagger}$ temperature variations affect gear idle rattle, which requires an understanding of the distributions of lubricant and heat within a gearbox. This paper presents the findings of a study of lubricant flow in a simple model gearbox by means of CFD (Computational Fluid Dynamics) and its validation by a series of tests on a spur gear rig. The commercial CFD code Fluent is used to simulate the splash flow of lubricant, using the techniques of dynamic meshing and VOF (Volume of Fluid). Our model takes into account the effects on the distribution of gear lubricant of lubricant level and physical properties as well as rotational speed. The results demonstrate that the flow patterns are strongly influenced by all these variables. The predictions are validated by high-speed flow visualisations using high-resolution imaging in conjunction with a pulsed Cu-vapour laser light source and powerful white light source. The simulated fluid flows are in good qualitative agreement with the experimental visualisation. Estimates of the velocity of oil droplets from the images are compared with CFD predictions of the velocity in regions with high lubricant-phase-fraction resulting from lubricant splashing.
\end{abstract}

\section{INTRODUCTION}

In most engineering applications in automotive and wind energy industries, gear lubrication is crucial for power transmission to maintain performance, durability and reduce power losses during all phases of gearbox operation [1-3]. Numerous experimental investigations have been carried out for many years. For example, Höhn et al. [3] have experimentally investigated the effects immersion level of lubrication on power loss, bulk temperature and scuffing load carrying capacity in a back-to-back FZG gear system. Luke and Olver [4] have studied the churning loss by measuring the churning torques against different speeds, lubricants and temperatures for a range of single gear. More recently, analytical and numerical approaches on the subject have also been developed. Diab et al. [5] have analytically studied the pumping effect of lubricant in a spur and helical test gear rig by solving discretised flow equations. Their studies indicated power losses resulting from lubricant pumping effect are dependent on angular velocity. Moshammer et al. [6] have predicted the flow pattern of lubricant around a test rig with single rotating gear by using the CFD commercial code Fluent. However, the scenario of lubricating meshed gears is much more complicated due to the different rotation direction of the two gears, the small-scale flow in the meshing zone and multiphase nature of the flow in splash-lubricated gears.

In this paper, we have applied VOF multiphase flow model and dynamic meshing to simulate the fluid flow during dip (splash) lubrication within a mating gear box. The simulation is validated by experimental results. The work is presented as follows. First we explain the experimental set-up. Subsequently, we give a brief summary of the chosen numerical method. In the final two sections we present the main body of our results along with discussion and conclusions.

\section{EXPERIMENTAL APPARATUS}

Table 1 The properties of lubricant and air

\begin{tabular}{l|cc}
\hline & Lubricant & Air \\
\hline Kinematic Viscosity & $34.9\left(40^{\circ} \mathrm{C}\right)$ & $16.6\left(40^{\circ} \mathrm{C}\right)$ \\
$\left(\mathrm{mm}^{2} / \mathrm{s}\right)$ & $7.2\left(100^{\circ} \mathrm{C}\right)$ & $22.9\left(100^{\circ} \mathrm{C}\right)$ \\
Viscosity Index & 141 & - \\
Density $\left(\mathrm{kg} / \mathrm{m}^{3}\right)$ & $871\left(15^{\circ} \mathrm{C}\right)$ & $1.1966\left(22^{\circ} \mathrm{C}\right)$ \\
Colour & Red & - \\
\hline
\end{tabular}

† Alternative term of "lubricant" unless stated. 
The main apparatus of experimental system includes DC power supply, test rig, high speed video camera, halogen light, data acquisition system and a pulsed Cu-vapour laser. The lubricant used in the experiment is Shell ${ }^{\circledR}$ Donax TA automatic transmission fluid at the room temperature of $22^{\circ} \mathrm{C}$. The physical properties of the working fluids - lubricant and air - are given in Table 1. The configuration of the facilities is shown in Figure 1. The experiment was carried out in Optical Engineering Laboratory at Loughborough University, UK.

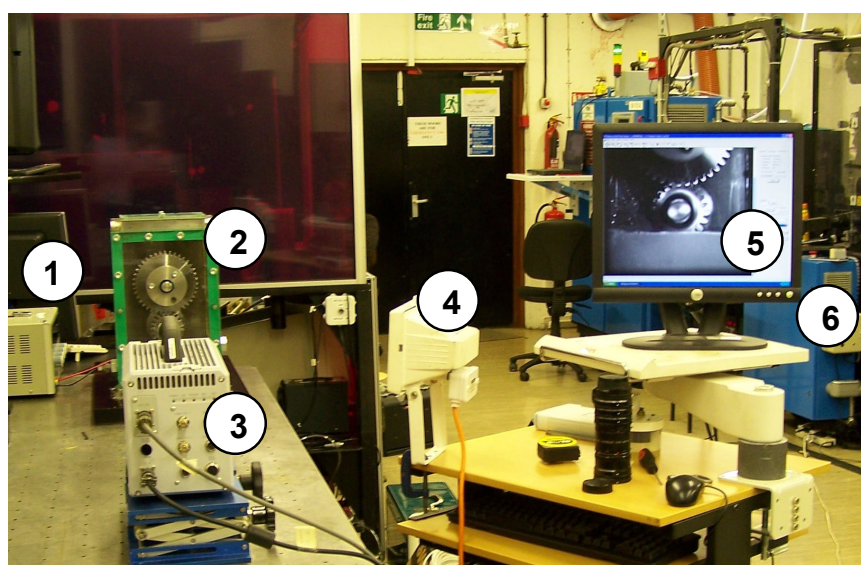

Figure 1 The configuration of the experiment. (1): C power supply, (2): test rig, (3): high speed video camera, (4): halogen light, (5): data acquisition system and (6): pulsed $\mathrm{Cu}$-vapour laser

\section{TEST RIG}

The overall dimensions of test rig are $300 \mathrm{~mm}$ height, $200 \mathrm{~mm}$ width and $100 \mathrm{~mm}$ depth. The wall thickness is $20 \mathrm{~mm}$ and bottom base is $40 \mathrm{~mm}$. The detail dimension is shown in Figure 2. The priority of the design is to maximise the amount of transparent wall area for flow visualisation without jeopardising the mechanical strength of the system. The material of top frame, bottom base and back plate is carbon steel for maintaining the stiffness of rig. The front and side walls are made of Perspex ${ }^{\circledR}$ which is also used to make a top cover. The gear assembly is bolted carefully to avoid cracking of the Perspex ${ }^{\circledR}$ window. The rotating elements are a pair of standard commercial standard duty spur gears manufactured by HPC Gears Ltd, UK. The specification of gears is displayed in Table 2. The diameter of the parallel shafts is $25 \mathrm{~mm}$. SKF deep groove ball bearings and cylindrical roller bearings were used in the high speed / low torque application of this non-loaded test rig.

\section{HIGH SPEED VIDEO CAMERA}

The lubricant flows were imaged by means of a Photron FASTCAM ultima APX-RX high speed video camera (HSVC) operating with an acquisition rate of 3,000 frames per second (fps) achieving full frame $1,024 \times 1,024$-pixels resolution. This frame rate was found to be sufficient to capture of all significant flow details for the range of angular velocity of $34-126 \mathrm{rad} / \mathrm{s}$ chosen for our experiments.

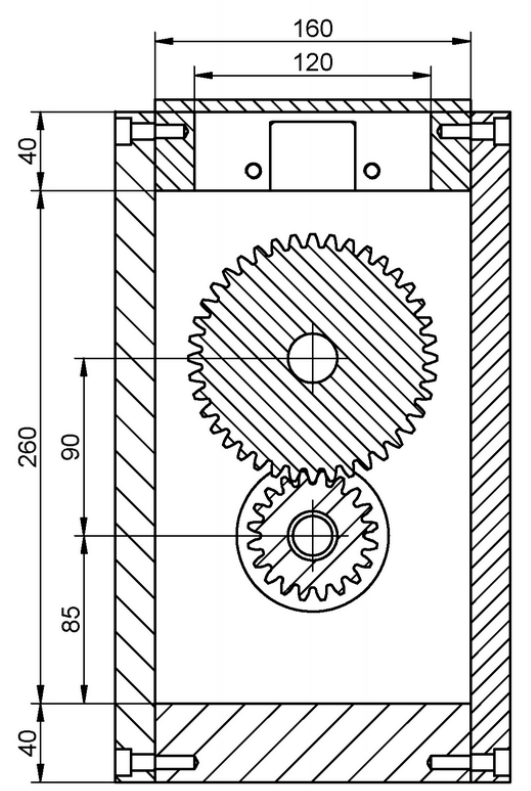

Figure 2 The sketch of section view of test rig, the units are $\mathrm{mm}$.

\section{LIGHTING SYSTEM}

The lighting is a key feature when filming fluid flow of gear lubrication. A $1 \mathrm{~kW}$ halogen lamp in side illumination was found to provide sufficient light for adequate contrast in many tests. In cases where sharp image contrast was required to reveal intricate flow detail at small scales a pulsed Cu-vapour laser system LS2050 manufactured by Oxford Lasers Ltd, UK was used. The system was operating at a wavelength of $510.6 \mathrm{~nm}$ (green), producing a nominal output power of 20 Watt. The flash duration of each laser pulse is $25 \mathrm{~ns}$ and the frequency and phase are synchronised with the shutter of the high-speed camera.

Table 2 Geometry of gears

\begin{tabular}{l|cc}
\hline & Wheel & Pinion \\
\hline Number of teeth & 40 & 20 \\
PCD $(\mathrm{mm})$ & 120 & 60 \\
Face width $(\mathrm{mm})$ & 30 & 30 \\
Module $(\mathrm{mm})$ & 3 & 3 \\
Pressure angle (degrees) & 20 & 20 \\
Material & Steel (214M15/045M15) \\
Backlash $(\mu \mathrm{m}$, measured) & \multicolumn{2}{|c}{323 (average) } \\
\hline
\end{tabular}




\section{NUMERICAL APPROACH}

The flows of lubricant and air inside the gearbox are driven by the rotation of the gears. The resulting fluid motion is a two-phase flow in an enclosure with stationary walls and two internal moving boundaries. The purpose of our investigation is (i) to resolve the flow patterns within the lubricant bath at the bottom of the gearbox, (ii) to identify regions of lubricant spray formation and (iii) to study the influence of speed of driving gear, immersion depth and viscosity of oil on the fluid flow of gear lubrication. The multiphase flow algorithm most suited to this task is the Volume of Fluid model. Dynamic meshing was used to enable the simulation of the motion of the gear pair, which is complicated by the fact that the solid boundaries rotate in opposite sense. The geometry of the gear pair including tooth involute profile was defined in SolidEdge ${ }^{\circledR}$. This geometry was meshed using the commercial preprocessor Gambit $^{\circledR}$. The CFD model was run in the commercial CFD code Fluent ${ }^{{ }^{8}}$ 6.3.26. The general approach to CFD modelling within this code is described extensively in the Fluent ${ }^{\circledR}$ User's Guide [7]. Because of limitations imposed by the available computational resource - Intel ${ }^{\circledR}$ Core $^{\mathrm{TM}} 2$ Duo processor at clock speed of $2.16 \mathrm{GHz}$ - the flow was modelled using a twodimensional solver.

\section{VOLUME OF FLUID (VOF) MULTIPHASE MODEL}

The VOF multiphase model, developed by Hirt and Nichols [8], is a fractional volume of fluid method to track free surfaces of two or more immiscible fluid regions. The model has been reviewed by Scardovelli and Zaleski [9] and Hewitt and Reeks [10] who claim VOF as a useful tool for investigating interfacial regime in multiphase flows. Recently, Löhner et al [11] proved the robustness of VOF technique for predicting the free surface flow using unstructured grid. Moshammer et al [6] has successfully simulated the oil distribution around a single rotating gear by using VOF model.

For the lubricant-air system in our gearbox, the method involves the solution of two transport equations: the momentum equation to compute the fluid motion and a volume fraction equation to resolve the distribution of the phases within the computational domain. The location of the interface between two immiscible fluids, such as lubricant and air can be determined from the distribution of volume fraction within the computational domain, since control volumes occupied only by lubricant or air have a volume fraction of 0 or 1 , respectively. Fluid properties within each control volume are computed on a volume-fraction-averaged basis, i.e., density, viscosity, are calculated as

$$
\varphi=\sum_{i=1}^{2} \alpha_{i} \varphi_{i}
$$

where $\varphi$ stands for the property of fluid and $\alpha$ the volume fraction. The sum of volume fractions $\alpha_{1}$ and $\alpha_{2}$ is of course unity: $\alpha_{1}+\alpha_{2}=1$.

\section{DYNAMIC MESH MODEL}

To cope with the intermeshing of the rotating gears it is necessary to select the dynamic mesh model in Fluent. The meshes in the vicinity of the gear pair are updated to follow the rotating motion at each time step by marking cells on the basis of cell skewness and maximum length scales. Computational cells are agglomerated and/or created when certain skewness or size criteria are violated, thus the mesh is automatically adapted to fit the boundary motion and be sufficiently smooth for computational stability.

The quality of initial mesh is crucial to the simulation result. After its generation it is inspected for skewness in Gambit. The size function was applied to obtain a very fine computational grid in vicinity of moving gear teeth particularly in the zone where the gear pair mated compared with the grid in the far field. The deforming zone (computational domain) is filled by more than 132,000 triangular cells. Figure 3 illustrates the initial two-dimensional mesh concept. The inset in Figure 3(a) shows the magnified dashed region in Figure $3(b)$. To obtain stable iterations with the dynamic mesh model, the cell skewness of the initial mesh should not exceed 0.7 .

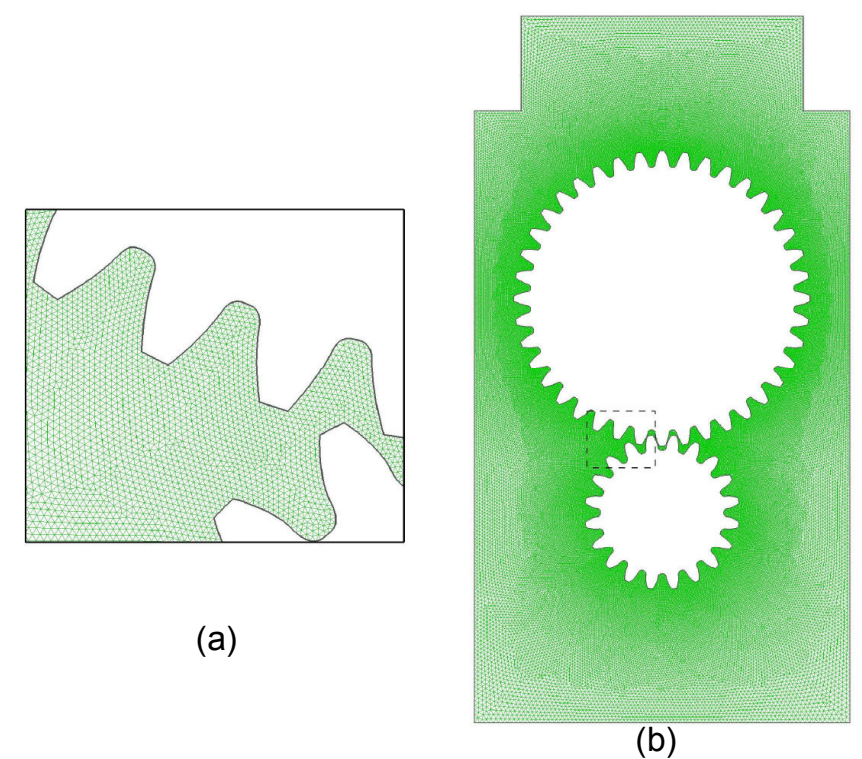

Figure 3 The gearbox geometry with meshes.

For high-speed mating gear, the backlash is a function of passage to prevent the lubricating oil trapped between meshes [12].The average normal backlash of our mounted gear pair was measured by dial gauge and found to be $323 \mu \mathrm{m}$. However, it is extremely difficult to mesh such narrow fluid zone at this level. To maintain continuity of the computational flow, the centre distance of gear pair is increased to $91 \mathrm{~mm}$, which was chosen as 
a compromise between physical realism and the difficulty of meshing. According the equation published in DIN standard [13], the artificial normal backlash used in the computation can be calculated as $738 \mu \mathrm{m}$.

\section{TURBULENCE MODEL}

The flow regime is turbulent and in these simulations the $k-\varepsilon$ turbulence model was selected to model the effect of turbulent fluctuations on the mean flow, since it is the most economical and computationally robust of the available turbulence models. The renormalization group (RNG) $k-\varepsilon$ turbulent model was chosen since it has been reported to have certain advantages in the modelling of rotating and swirling flows [7].

\section{BOUNDARY CONDITIONS}

In the experiment, the rotational speed is monitored by handhold digital tachometer. The fluctuation of speed is observed at $\pm 5 \mathrm{rad} / \mathrm{s}$. Two average driving rotational speeds - 34 and $126 \mathrm{rad} / \mathrm{s}$, respectively - are applied to the pinion for the simulation set-up. The rotating direction of pinion is clockwise through the paper. The gear motion is described by means of a user-defined, compiled $\mathrm{C}++$ function (UDF). Moshammer et al [6] found that the spray patterns of lubricant rely upon additional artificial wall roughness compensation to "virtual tooth". However, the wall roughness parameters don't contribute more effect on the flow pattern in this study. The nominal roughness of wall is $0.35 \mu \mathrm{m}$ in conjunction with a roughness factor of 0.5 . The contact angle of lubricant-to-air is taken a value of $30^{\circ}$ as recommended in the Fluent manual. The no-slip boundary condition is set on stationary enclosure walls along with the roughness values mentioned above. The initial lower level of lubricant is an immersion depth of 3 times the module and the higher level one is 6 times the module (i.e. $9 \mathrm{~mm}$ and $18 \mathrm{~mm}$, respectively).

\section{DISCRETISATION PRACTICE}

To approximate the shape of the oil/air interface, the geometric reconstruction scheme was used in the study. The scheme represents the interface between two phases using a piecewise-linear method to approach a linear slope within each cell for unstructured grid. The PISO algorithm was chosen for the pressure-velocity coupling in the segregated solver. PISO has a skewness correction feature which is recommended for the modelling of transient flows on highly distorted meshes. Because the mesh is re-generated at each time step in the simulation, this algorithm improves the stability of calculation at a reasonable time step. The main transported quantities were discretised using the secondorder upwind scheme. Pressure interpolation was handled using PRESTO! discretisation scheme for a high speed rotating flow with unstructured mesh in the VOF multiphase model. The recommended settings of the under-relaxation factor [7] were used to control the update of computed variables at each iteration.

\section{RESULTS AND DISCUSSION}

\section{THE EFFECT OF ROTATIONAL SPEED ON FLUID FLOW}

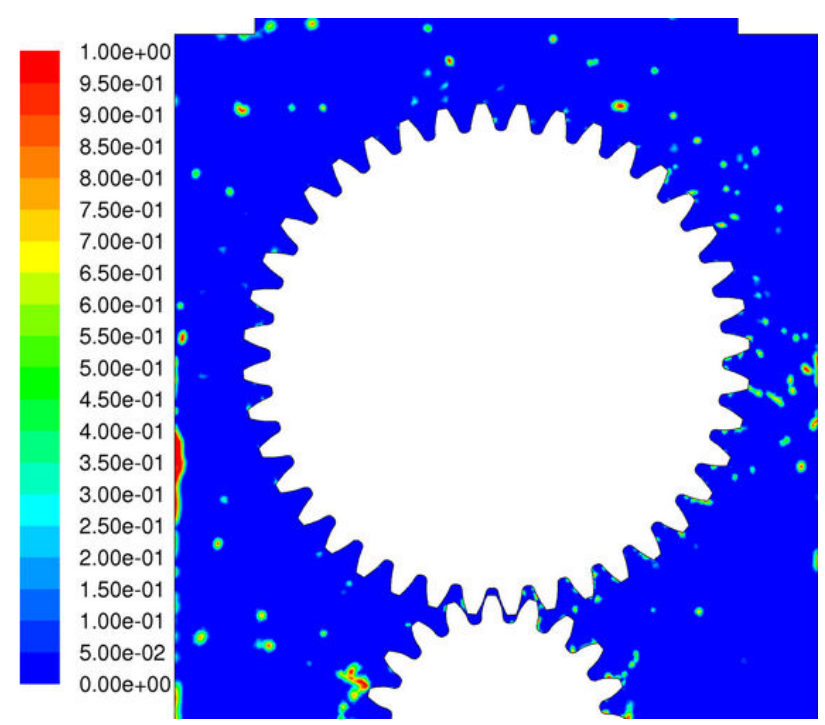

(a)

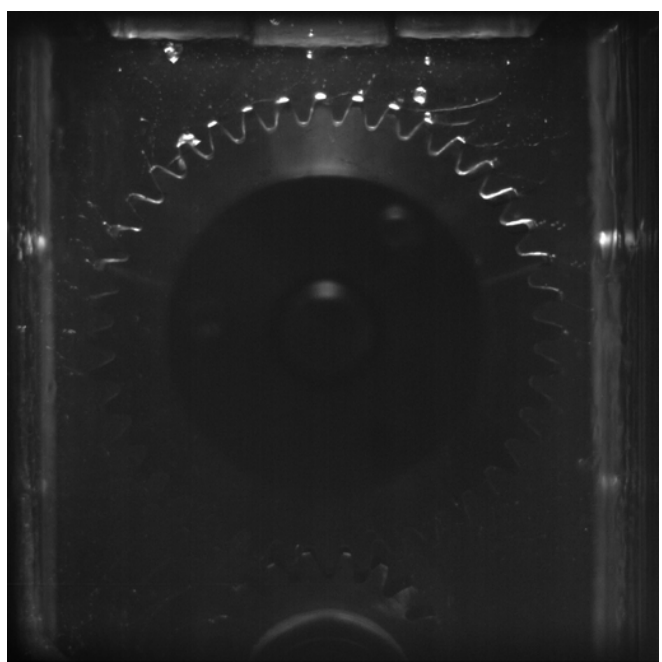

(b)

Figure 4 The comparison of simulation (a) and experiment (b) results for oil splash pattern followed the motion of wheel. The legend in (a) indicates the volume fraction

Figure 4 shows a comparison of the computed and experimental flow patterns with a rotational pinion speed of $34 \mathrm{rad} / \mathrm{s}$. When a rotated gear is partly immersed in the lubricant, the speed is one of key factors to determine the fluid flow resulting in oil churning power loss [12]. At the lower lubricant level of $3 \mathrm{~mm}$, the oil is stirred up by pinion teeth. A portion of the oil subsequently moves upwards with the gear wheel towards the meshing area. A small amount of oil is squeezed back from the meshing zone to left sidewall in this case where the pinion rotation is clockwise. The rest 
of oil is pressed through the meshing point following the motion of gear pair and splashes towards the right sidewall. A thin oil film adheres to the teeth flank of gear and pinion, respectively. As it travels with the gear motion, oil mists and drops are ejected along a parabolic path due to the centrifugal force. The larger oil falls due to gravity. In Figure 4, the experimental observation of oil splashing followed wheel motion can be fairly predicted by using CFD simulation. (After the pinion rotated more than $720^{\circ}$, the simulation is regarded as a quasi-steady state owing to the rotating loop. All the snapshots of the simulation in the paper are occurred after two revolutions of the pinion.)

Figure 5 compares detail images of fluid flow near the pinion at low and high angular velocity. This shows that more lubricant is brought to the meshing zone when the speed increased up to $126 \mathrm{rad} / \mathrm{s}$ (see Figure 5(c)). The increase of the amount of oil brought into the meshing zone will result in higher churning power losses (compare Figures 5(b) and 5(d)). The high-speed video camera images provide reasonable validation of the CFD simulations by the experiments. Using the empirical equations in AGMA information sheet [14], the gears windage and churning losses at the speed of $34 \mathrm{rad} / \mathrm{s}$ can be calculated as 0.121 watt at steady state. However, the power losses increase to 6.16 watt for the pinion rotational speed at $126 \mathrm{rad} / \mathrm{s}$. The CFD predictions provide clear information of the more power loss as a result of higher speed. The same conclusion was drawn by Luke and Olver [4] and Yada [15] through the observation of experiment.

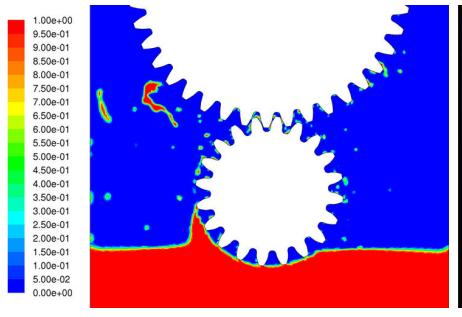

(a)

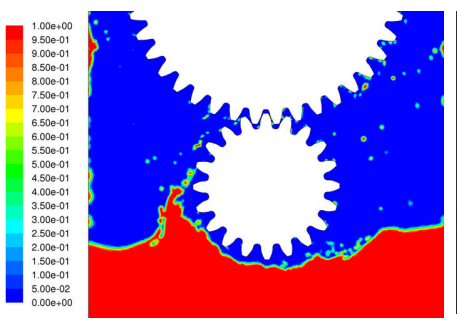

(c)

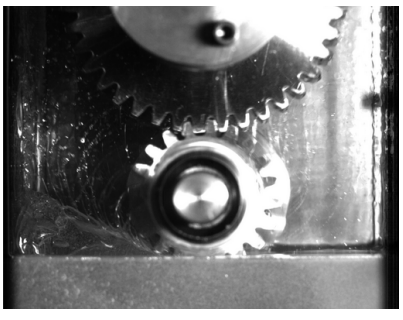

(b)

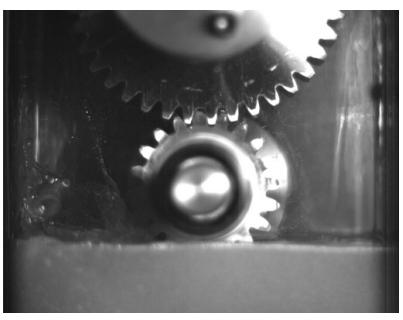

(d)
Figure 5 The comparison of simulation and experiment results of fluid flow for different

rotational speed of pinion. (a) \& (b): $34 \mathrm{rad} / \mathrm{s}$, (c) \& (d): $126 \mathrm{rad} / \mathrm{s}$. The legend in (a) \& (c) indicates the volume fraction.
THE EFFECT OF IMMERSION DEPTH ON FLUID FLOW

The level of lubricant in an enclosed gear box is another key factor to influence the windage and churning power losses [3-4]. The computations in Figure 6 clearly show that an increase of the oil level from 3 to 6 times of module causes more oil to be hurled up by the rotating gear motion. Figures $6(a-b)$ show the results for a pinion angular velocity of $34 \mathrm{rad} / \mathrm{s}$. Whereas in Figures 6(c-d) give the corresponding results for the higher angular velocity speed of $126 \mathrm{rad} / \mathrm{s}$, which show the same flow trend, but with a stronger churning pattern. In their experiment, Höhn et al [3] found the same flow trend in horizontal mounted FZG test rig when the immersion depth of oil was changed.

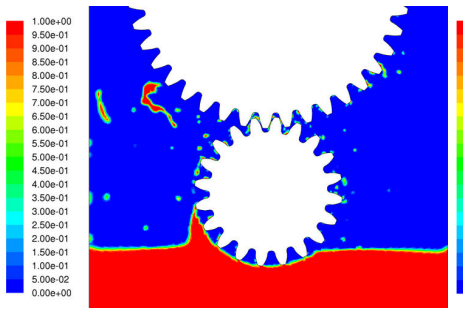

(a)

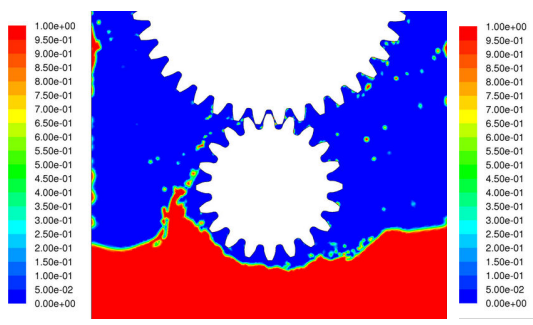

(c)

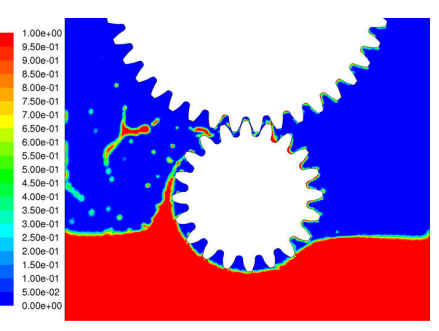

(b)

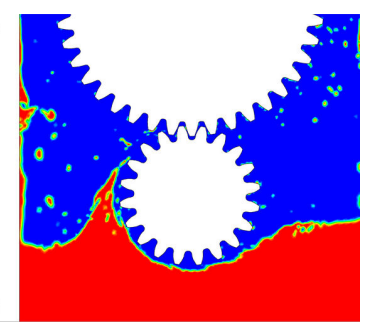

(d)
Figure 6 The comparison of simulation and experiment results of fluid flow for different immersion depth of lubricant. (a) \& (b): $34 \mathrm{rad} / \mathrm{s}$, (c)

$\&$ (d): $126 \mathrm{rad} / \mathrm{s}$. The legend indicates the volume fraction.

\section{THE EFFECT OF OIL VISCOSITY ON FLUID FLOW}

Studies have shown that oil temperature strongly affects gear box noise [16-19], which suggests that heat transfer plays an important part in determining levels of idle gear rattle. This has been attributed to increase of the resistance to relative motion in lubricated contacts as the oil viscosity increases with decreasing temperature. To examine the effect of viscosity on the gear lubrication flow regime, the higher viscosity oil is applied. The viscosity of oil is equivalent to ISO 220 which kinetic viscosity is $455.84 \mathrm{~mm} / \mathrm{s}^{2}$ and density is $894.98 \mathrm{~kg} / \mathrm{m}^{3}$ at $22{ }^{\circ} \mathrm{C}$. After $890^{\circ}$ revolutions of the pinion, the comparison of viscosity effects on the fluid flow is illustrated in Figure 7. For higher viscosity oil, there is not more splashing on the right sidewall. Instead of splash, most oil between the meshes sticks with the teeth flank and circulates with the gear motion. But, the oil at the left 
side of pinion is churned up and more oil suspends in the air due to the strong viscous effect of the lubricant. The churning pattern is more vigorous than its counterpart in low viscosity oil (Figure 7(a)). It demonstrates that the higher viscosity of lubricant employed in the test rig, the more churning power losses. Using the same method above, the windage and churning losses is 1.02 watt for the high viscosity oil case compared to 0.121 watt for the low viscosity one. The finding is consistent with the conclusion drawn by Kubo et al. [20] and Michaelis and Höhn [21] in their experimental investigations.

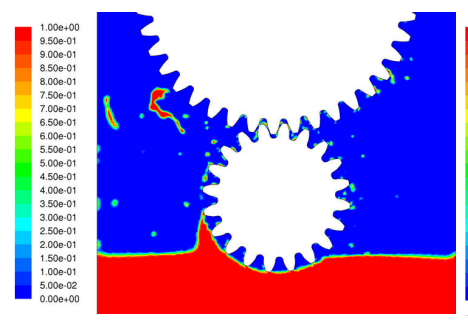

(a)
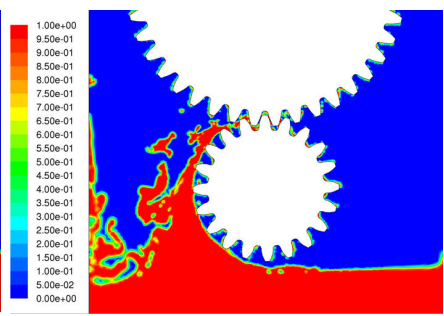

(b)
Figure 7 The comparison of simulation and experiment results of fluid flow for different viscosity of lubricant. The pinion rotational speed is $34 \mathrm{rad} / \mathrm{s}$ and the legend indicates the volume fraction.

\section{CONCLUSION}

A numerical investigation on gear lubrication was conducted in the paper. The predictions were compared with experimental results on a spur gear test rig designed to investigate the effects of speed, immersion depth and viscosity of oil on the fluid flow. The flow pattern of oil in the gear box was found to be significantly influenced by rotational speed because of the lubricant bath was agitated by the dipping gear and as a result part of the oil follows the motion of the gear wheel. At higher speed, more oil is brought up leading to higher power losses. An increase of the immersion depth of oil was also found to cause an increase of the volume of stirred oil. The higher viscosity oil employed for gear lubrication, the more oil is churned up leading to churning power losses increase.

The trends indicated by the CFD model also agree with those reported elsewhere in the literature. However, we recognise that more costly $3 D$ CFD simulations will be necessary to provide information on axial flow, which cannot be accounted for in our present 2D model. Furthermore, heat transfer between the gear box and its surroundings will generate non-uniform oil temperature distributions, highlighting possible limitations of our current assumption of constant lubricant viscosity. A programme of work is in progress to incorporate these effects in our simulations.

\section{ACKNOWLEDGMENTS}

The research project is financially supported by Department for Business, Enterprise and Regulatory Reform, UK and Romax Technology Ltd, UK under contract number KTP001293.

\section{REFERENCES}

1. Dowson, D., "The role of lubrication in gear design", Proceedings of the Institution of Mechanical Engineers, 184(315), 72-78, 1969.

2. Olver, A. V., "Gear lubrication - a review", Proceedings of the Institution of Mechanical Engineers, Part J: Journal of Engineering Tribology, 216(5), 255-267, 2002.

3. Höhn, B. R., Michaelis, K. and Otto, H. P., "Influence of immersion depth of dip lubricated gears on power loss, bulk temperature and scuffing load carrying capacity", International Journal of Mechanics and Materials in Design, 3(3), 1-16, 2007.

4. Luke, P. and Olver, A. V., "A study of churning losses in dip-lubricated spur gears", Proceedings of the Institution of Mechanical Engineers, Part G: Journal of Aerospace Engineering, 213(5), 337-346, 1999.

5. Diab, Y., Ville, F., Houjoh, H., Sainsot, P. and Velex, P., "Experimental and numerical investigations on the air-pumping phenomenon in high-speed spur and helical gears", Proceedings of the Institution of Mechanical Engineers, Part C: Journal of Mechanical Engineering Science, 219(8), 785-800, 2005.

6. Moshammer, T., Mayr, F., Kargl, K. and Honeger, C. Simulation of oil flow in gear box housing. In 2006 SAE World Congress. Detroit, Michigan, SAE, 2006-01-1574, 2006.

7. Fluent, "FLUENT 6.3 User's Guide." Fluent Inc., Lebanon, NH 2006.

8. Hirt, C. W. and Nichols, B. D., "Volume of fluid (VOF) method for the dynamics of free boundaries", Journal of Computational Physics, 39(1), 201-225, 1981.

9. Scardovelli, R. and Zaleski, S., "Direct numerical simulation of free-surface and interfacial flow", Annual Review of Fluid Mechanics, 31(1), 567-603, 1999.

10. Hewitt, G. F. and Reeks, M. W., "Computational modelling of multi-phase flows". In G.F. Hewitt and C. Vassilicos (Eds.), Prediction of Turbulent Flows. 
Cambridge University Press, Cambridge, p. 236, 2005.

11. Löhner, R., Yang, C. and Oñate, E., "Simulation of flows with violent free surface motion and moving objects using unstructured grids", International Journal for Numerical Methods in Fluids, 53(8), 1315-1338, 2007.

12. Townsend, D. P. (Ed.), Dudley's Gear Handbook. McGraw-Hill Inc., New York.1991.

13. DIN, "Definitions on involute cylindrical gears and gear pairs, classification of the equations." Deutsches Institut für Normung, Berlin, DIN 3960 Supplement 1, 1980.

14. AGMA, "Gear reducers - Thermal capacity based on ISO/TR 14179-1." AGMA, Alexandria, VA, USA, AGMA ISO 14179-1, 2004.

15. Yada, T., "Relation of frictional loss of gear to speed and torque", Bulletin of JSME, 16(95), 872-880, 1973.

16. Sakai, T., Doi, Y., Yamamoto, T., Ogasawara, M., and Narita, M., "Theoretical and experimental analysis of rattling noise of automotive gearbox", SAE Technical Paper 810773, 1981.
17. Seaman, R. L., Johnson C. E. and Hamilton, R. F., "Component inertial effects on transmission design", SAE Technical Paper 841686, 1984.

18. Fujimoto, T., Chikatani, Y. and Kojima, J., "Reduction of idling rattle in manual transmission", SAE Technical Paper 87035, 1987

19. Fujomoto, T. and Kizuka, T., "An improvement of the prediction method of the idling rattle in manual transmission - in the case of the manual transmission with backlash eliminator", SAE Technical Paper 2001-01-1164, 2001.

20. Kubo, K., Shimakawa, Y. and Kibukawa, M., "The effect of gear oil viscosity and friction reducer type on transmission efficiency", Tribology International, 19(6), 312-317, 1986.

21. Michaelis, K. and Höhn, B. R., "Influence of lubricants on power loss of cylindrical gears", Tribology Transactions, 37(1), 161-167, 1994. 